\title{
Phylogeographic analysis of the mid-Holocene Mammoth from Qagnax̂ Cave, St. Paul Island, Alaska
}

\author{
J.M. Enk ${ }^{\text {a,* }}$, D.R. Yesner ${ }^{\text {b }}$, K.J. Crossen ${ }^{c}$, D.W. Veltre ${ }^{\text {b }}$, D.H. O'Rourke ${ }^{\text {a }}$ \\ a Department of Anthropology, University of Utah, 270 S 1400 E, Rm 102, Salt Lake City, UT 84112, USA \\ b Department of Anthropology, University of Alaska, 3211 Providence Dr., Rm 212, Anchorage, AK 99508, USA \\ c Department of Geological Sciences, University of Alaska, 3211 Providence Dr., Rm 212, Anchorage, AK 99508, USA
}

\section{A R T I C L E I N F O}

\section{Article history:}

Received 21 May 2008

Received in revised form 22 November 2008

Accepted 23 December 2008

\section{Keywords:}

Woolly mammoth

Ancient DNA

Beringia

Pribilof Islands

Holocene refugia

\begin{abstract}
A B S T R A C T
Remains of a woolly mammoth (Mammuthus primigenius) were found in Qagnâx Cave, a lava tube cave on St. Paul Island in the Pribilof Islands, $500 \mathrm{~km}$ west of the Alaskan mainland in the Bering Sea. Several dates converge on $5725{ }^{14} \mathrm{C}$ yr BP, making these the youngest mammoth remains discovered in North America, and among the few Holocene mammoths known. Genetic analysis of the cytochrome $b$ gene and adjacent regions of the mitochondrial genome demonstrates that the Qagnax̂ mammoth is highly derived, possessing several unique polymorphisms not found in other mammoths. However, while this is consistent with a recent insular isolation scenario, phylogenetic analysis suggests that the specimen represents a population whose isolation from other mammoths occurred at or well before the terminal Pleistocene submergence of the Bering Land Bridge. It is possible that it represents a member of a "land bridge subclade" of woolly mammoths that remained distinct from mainland Alaskan populations, but was not restricted to highland areas until the land bridge was submerged. Additional eastern Beringian, and particularly insular, mammoth DNA sequences are required to explore this possibility.
\end{abstract}

(C) 2008 Elsevier B.V. All rights reserved.

\section{Introduction}

A mid-Holocene vertebrate faunal assemblage including woolly mammoth [Mammuthus primigenius (Blumenbach, 1799)] has recently been obtained from Qagnax Cave, a lava tube cave on St. Paul Island in the Pribilof Islands. Approximately $90 \mathrm{~km}^{2}$ in area, St. Paul Island is one of two smaller and three larger islands comprising the Pribilof Islands group in the eastern Bering Sea (Fig. 1). The islands are among the most isolated places in North America, lying some $500 \mathrm{~km}$ WSW from the nearest point on the Alaskan mainland and $400 \mathrm{~km} \mathrm{NW}$ of the eastern Aleutian Islands. Like the eastern Aleutian Islands, the Pribilofs were separated from the Alaskan mainland by at least 13,000 ${ }^{14} \mathrm{C}$ yr BP, gradually shrinking in size, achieving their present size of $\sim 90 \mathrm{~km}^{2}$ by around $5000{ }^{14} \mathrm{C}$ yr BP, when sea level rose to within $4 \mathrm{~m}$ of its current position before stabilizing (Manley, 2002; Guthrie, 2004). Since no prehistoric archaeological sites have been found on the islands, it is likely that their isolation resulted in an absence of human occupation prior to their 1786 discovery by Russian sailors and the subsequent transport there of Aleut (Unangan) people.

Mammoth remains have occasionally been documented from St. Paul Island over the past 100 years. Initial discoveries of mammoth

\footnotetext{
* Corresponding author. Department of Anthropology, University of Utah, 270 S 1400 E, Rm 102, Salt Lake City, UT 84112-0060, USA. Tel.: +1 801581 6251; fax: +1 801581 6252.

E-mail address: jake.enk@utah.edu (J.M. Enk).
}

remains were detritally derived from coastal erosion; Stanley-Brown (1892), Preble (1923), and Ray (1971), for example, all reported the discovery of mammoth tusks or molar teeth from Northeast Point on St. Paul Island. Among all of the Bering Sea islands, however, St. Paul Island in the Pribilofs is unique in possessing lava tube caves from which animal bones have been collected. An 1897 expedition under R.E. Snodgrass and D.S. Jordan obtained two mammoth teeth from Bogoslof Cave (Stanley-Brown, 1892; Preble, 1923), but they were lost in transit to the Smithsonian Institution in 1904 and never recovered (Ray, 1971). Qagnax Cave, in the central highlands of the island, was discovered by hunters in August 1999. The cave was initially tested in 2000 as a part of an archaeological project conducted by Veltre and McCartney (2002), and was followed by more intensive collection during 2003 (Crossen et al., 2003). Hundreds of animal bones and mammoth tooth plates were collected from the floor of the cave, which had apparently served as a natural trap for local animal populations. Seven mammoth bones were recovered, including four molar teeth (two partial and two nearly complete) and three postcranial bones, at least one of which is a proximal scapula fragment, including the glenoid facet. Hundreds of additional mammoth molar plate fragments were spread among 24 collection units.

Dates of bones and mammoth teeth, using both AMS and conventional methods, yielded nearly identical results ranging from 5630 to $5800{ }^{14} \mathrm{C}$ yr BP, with most dates falling between 5710 and 5740 yr ${ }^{14} \mathrm{C}$ yr BP (Crossen et al., 2003; Guthrie, 2004; Veltre et al., 2004; Crossen et al., 2005; Yesner et al., 2005a,b). The high degree of 


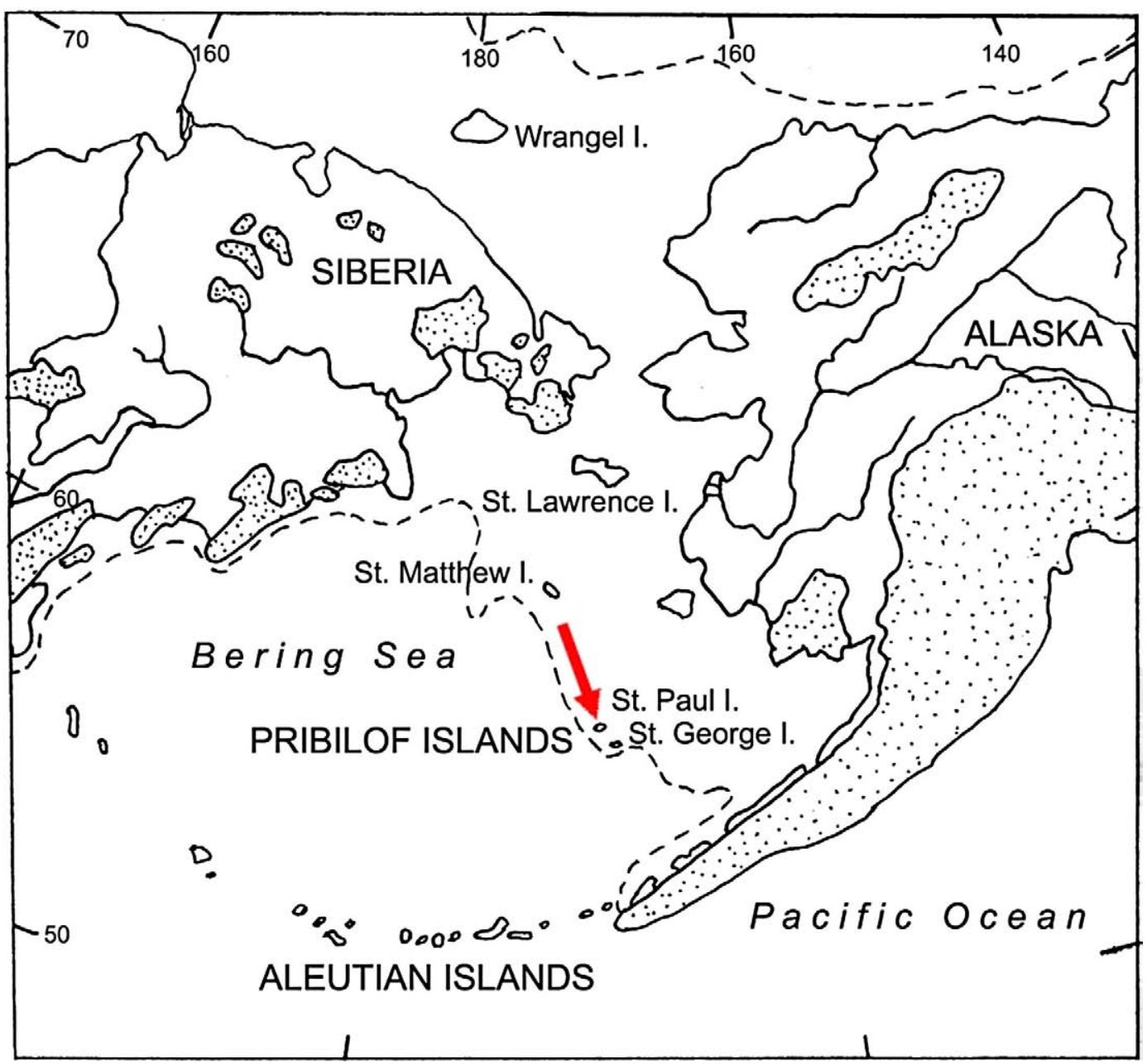

Fig. 1. Coastline (dashed lines) and glaciated regions (shaded areas) of Beringia at $\sim 14,000{ }^{14} \mathrm{C}$ yr BP. Arrow points to St. Paul Island. Adapted from Yesner et al. (2005b).

similarity in both tooth and bone dates suggests that all of the specimens may have derived from a single individual mammoth, with a pooled mean age of $5725 \mathrm{yr}$ BP. Slightly older dates have been obtained by Guthrie (2004) and Grover and Tedor (2006) on detrital mammoth specimens from the Pribilofs; these are the youngest mammoth dates ever produced in North America. Morphological characters of the molar teeth of the Qagnax mammoth (Maglio, 1973; Haynes, 1991; Veltre et al., 2008) suggest that this individual is consistent with other terminal Pleistocene specimens, sometimes considered at the small end of the size range for woolly mammoth (Lister, 1996; Stuart et al., 2002), but not a truly dwarfed individual in the sense of the California Channel Island mammoths (Mammuthus exilis) (Agenbroad, 2003).

The Qagnax mammoth offers a unique case study for research in woolly mammoth phylogeography, due to both its insular context and very recent date. Accordingly, we isolated mtDNA from the Qagnax̂ mammoth to help elucidate its evolutionary and taxonomic status. Our primary research goal was to determine the degree and depth of isolation of the Qagnax mammoth relative to both eastern and western Beringian mammoths, as well as whether the presence of mammoths on St. Paul might be related to human-induced population displacement from mainland areas during the LGM.

\section{Results}

We targeted a continuous sequence of the mitochondrial genome including the cytochrome $b$ gene, two adjacent tRNA genes, and the first portion of the control region. We designed 30 primer pairs using all available definitive M. primigenius mitochondrial sequences (Yang et al., 1996; Ozawa et al., 1997; Noro et al., 1998; Greenwood et al., 1999; Debruyne et al., 2003; Krause et al., 2006; Rogaev et al., 2006; Barnes et al., 2007; Gilbert et al., 2007; see recently Gilbert et al., 2008 and Debruyne et al., 2008 for more sequences). These primers provide thorough overlap between targeted PCR amplicons (see Table 1). Seven of $9(77.8 \%)$ individual extracts yielded positive PCR products. Of two hundred thirty-three PCR amplification attempts, 94 (40.3\%) were successful. A single reaction indicated some degree of contamination and was removed from the analysis. Only one hundred eighty-three of 233 PCR attempts were necessary to build thorough sequence coverage, and 60 (32.8\%) of these were successfully amplified. We used these sixty positive amplification products for sequencing, resulting in a total of 107 individual sequencing reactions. A summary of PCR success rate per primer pair, as well as the sequencing reactions obtained for each extract/PCR are also included in Table 1.

The final 107 sequencing reactions provided enough overlap such that each nucleotide position is corroborated by at least 2 (and up to 9) independent extracts, at least 2 (and up to 9) independent PCRs, and at least 2 (and up to 16) individual sequencing reactions. Of the 1652 bp obtained, 31 positions (1.9\%) were determined with less than $100 \%$ consensus among individual sequencing reactions. However, all bases have $75 \%$ or greater consensus among the reactions obtained. For those positions with less than $100 \%$ consensus among sequencing reactions, a summary of the results is included in Table 2 . When compared to all available mammoth sequences, we observed 9 transitions unique to the Qagnâx mammoth, representing $0.54 \%$ sequence divergence for this individual among all other mammoths. 
Table 1

Primer map, PCR and sequencing results

\begin{tabular}{|c|c|c|c|c|}
\hline Pair $^{\mathrm{a}}$ & Position $^{\mathrm{b}}$ & $\mathrm{BP}^{\mathrm{c}}$ & $\mathrm{PCRs}^{\mathrm{d}}$ & Sequences ${ }^{\mathrm{e}}$ \\
\hline$\overline{1.1}$ & $5^{\prime} 14106-142163^{\prime}$ & 155 & $2 / 6$ & $3 b, 5 b$ \\
\hline 1.2 & $5^{\prime} 14182-143013^{\prime}$ & 165 & $3 / 3$ & $3 b, 5 b$ \\
\hline 1.3 & $5^{\prime} 14301-144763^{\prime}$ & 219 & $2 / 15$ & $4 \mathrm{~b}$ \\
\hline 1.4 & $5^{\prime} 14456-146013^{\prime}$ & 185 & $5 / 14$ & $1 \mathrm{~b}, 3 \mathrm{~b}, 4 \mathrm{r}, 5 \mathrm{r}$ \\
\hline 1.5 & $5^{\prime} 14596-146853^{\prime}$ & 131 & $2 / 2$ & $1 b, 2 b$ \\
\hline 1.6 & $5^{\prime} 14658-147453^{\prime}$ & 130 & $4 / 6$ & $4 b, 5 b$ \\
\hline 1.7 & $5^{\prime} 14702-148023^{\prime}$ & 141 & $2 / 2$ & $1 b, 2 b$ \\
\hline 1.8 & 5' 14793-14926 3' & 176 & $2 / 4$ & $4 b, 5 b$ \\
\hline 1.9 & $5^{\prime} 14886-149953^{\prime}$ & 161 & $2 / 6$ & $2 f$ \\
\hline 1.10 & $5^{\prime} 14916-150243^{\prime}$ & 154 & $1 / 4$ & $3 b$ \\
\hline 1.11 & $5^{\prime} 14936-151573^{\prime}$ & 264 & $3 / 5$ & $1 b, 2 b, 3 f$ \\
\hline 1.12 & $5^{\prime} 15123-152543^{\prime}$ & 172 & $4 / 9$ & $1 b, 3 b, 4 b, 5 b$ \\
\hline 1.13 & $5^{\prime} 15179-153323^{\prime}$ & 198 & $3 / 6$ & $1 b, 3 b, 5 b$ \\
\hline 2.1 & $5^{\prime} 14182-143153^{\prime}$ & 177 & $4 / 17$ & $1 \mathrm{bf}, 2 \mathrm{ff}$ \\
\hline 2.2 & $5^{\prime} 14301-144353^{\prime}$ & 177 & $1 / 5$ & $5 b$ \\
\hline 2.3 & $5^{\prime} 14339-144763^{\prime}$ & 181 & $5 / 7$ & $3 f, 4 f, 5 f$ \\
\hline 2.4 & $5^{\prime} 14793-148713^{\prime}$ & 125 & $3 / 4$ & $4 b, 5 r$ \\
\hline 2.5 & $5^{\prime} 14936-150243^{\prime}$ & 134 & $2 / 3$ & $1 \mathrm{f}, 3 \mathrm{f}$ \\
\hline 2.6 & $5^{\prime} 14969-150943^{\prime}$ & 170 & $2 / 6$ & $4 b, 5 b$ \\
\hline 2.7 & $5^{\prime} 15179-152543^{\prime}$ & 116 & $2 / 2$ & $2 \mathrm{r}$ \\
\hline 2.8 & $5^{\prime} 15219-153323^{\prime}$ & 158 & $1 / 4$ & $5 b$ \\
\hline 3.1 & $5^{\prime} 14106-141623^{\prime}$ & 101 & $2 / 2$ & 1f \\
\hline 3.2 & $5^{\prime} 14339-144433^{\prime}$ & 149 & $3 / 4$ & $1 b, 2 b$ \\
\hline 3.3 & $5^{\prime} 14824-149263^{\prime}$ & 146 & $3 / 4$ & $1 b, 2 b$ \\
\hline 4.1 & $5^{\prime} 15276-153713^{\prime}$ & 140 & $4 / 8$ & $8 b, 9 b$ \\
\hline 4.2 & $5^{\prime} 15370-154753^{\prime}$ & 127 & $4 / 9$ & $8 b, 9 b$ \\
\hline 4.3 & $5^{\prime} 15443-155363^{\prime}$ & 136 & $3 / 3$ & $8 b, 9 b$ \\
\hline 4.4 & $5^{\prime} 15535-156123^{\prime}$ & 120 & $5 / 7$ & $8 b, 9 b$ \\
\hline 4.5 & $5^{\prime} 15602-157243^{\prime}$ & 167 & $3 / 4$ & $8 b, 9 b$ \\
\hline $4.6^{\mathrm{f}}$ & $5^{\prime} 15700-157843^{\prime}$ & 130 & $5 / 12$ & $8 \mathrm{r}, 9 \mathrm{r}$ \\
\hline
\end{tabular}

a Primer pair ID\#; format is [Group].[\#].

b Base positions (mitochondrion) flanked by each primer pair.

c Amplicon length, including primers.

d PCR results; format is [\# Successful]/[\# Attempts].

e Sequences used of each primer pair; format is [Extract\#][direction], where " $\mathrm{f}$ " = forward sequence, " $\mathrm{r}$ " = reverse sequence, and " $\mathrm{b}$ " = both directions.

${ }^{\mathrm{f}}$ The reverse primer for this pair is from Barnes et al. (2007).

Each of these polymorphisms is corroborated by $100 \%$ (2/2 to 9/9) of the sequencing reactions covering them (also included in Table 2). We believe that the thorough coverage and consistency of multiple sequencing reactions from multiple independent extracts and amplifications sufficiently controls for any potential taphonomic damage or faulty incorporation of base pairs during experimental reactions. Thus, we are confident that our experiments provide a valid DNA sequence for this specimen.

It is interesting to note, however, that we observed multiple instances of damage/misreads at certain base positions. Of the thirtyone sites with less than $100 \%$ consensus among sequencing reactions, 15 exhibited damage (non-consensus calls) in at least two of the sequences obtained for those sites. For six of these 15 sites, nonconsensus calls were obtained not only from independent sequencing reactions, but also from independent extracts. Most of the chromatograph peaks at these sites were indeterminate nucleotides in one or both of the 'damaged' sequencing reads. However, at a single position (14388), two (of 5) independent extracts yielded identical and confident non-consensus nucleotides $(\mathrm{T})$. The occurrence of damage/ misreads at the same site in two independent reactions is especially good evidence for the "damage hotspot" phenomenon (Gilbert et al., 2003a,b). In light of this, we note that three of the transitions unique to Qagnax are only corroborated by 2 independent extracts/PCRs/ sequencing reactions as well; however, each is a type 1 ( $G>A$ or $T>C$ ) rather than type $2(A>G / C>T)$ transition. The latter transition type is considered a much more likely consequence of post-mortem cytosine deamination (Gilbert et al., 2003b). This fact, combined with the high consensus rate for these sites, lead us to conclude that these are in fact in vivo mutations.

\subsection{Phylogenetic analysis}

Our computed maximum likelihood and Bayesian trees are presented in Fig. 2b and c, coupled with nodal bootstrap values and posterior probabilities. Referring to topological features outlined by Barnes et al. (2007), it is evident that the Qagnax̂ mammoth sorts at the base of clade 1, along with two mainland Alaskan mammoths. However, the Qagnax̂ mammoth is considerably derived, representing a unique lineage within its clade. Taken on topological features only, the Qagnax and all clade 1 mammoths, as well as the other Alaskan mammoths, shared common ancestry sometime before the death of sample $\mathrm{AK}>41027$, which has an infinite radiocarbon date.

\section{Discussion}

Based solely on topological features, its relatively ancient common ancestry with other mammoths suggests that the Qagnâx mammoth was isolated from mainland Alaskan mammoths long before its arrival on St. Paul Island (peri- to pre-Last Glacial Maximum), and likely before $13,000{ }^{14} \mathrm{C}$ yr BP, when the island became separated from the Alaskan mainland (Guthrie, 2004). This does not suggest that the Qagnax̂ mammoth was displaced from mainland Alaskan populations by Pleistocene humans. If this had been the case, we would expect Qagnax to share most recent common ancestry with the younger Alaskan specimen (AK 15540) to the exclusion of the infinitely-dated Alaskan (AK>41027). This early-isolation scenario contrasts with conclusions drawn from analysis of mammoths occupying other Holocene refugia. A Wrangel Island mammoth, for instance, analyzed here and by Barnes et al. (2007), likely became reproductively isolated from mainland populations only after its arrival on the island, since it sorts very closely with other western Beringian mammoths in clade 1. The Qagnax̂ mammoth, on the other hand, does not share close affinity with either the Alaskan or Siberian members of clade 1. In light of this, we hypothesize that the Qagnâx mammoth represents a population that was native and restricted to the Bering Land Bridge itself, the remnants of which were gradually displaced to highland areas as sea levels rose after the LGM. The land bridge subclade hypothesis is difficult to test, as sampling mammoths from what was once the land bridge, in the absence of seafloor excavation, would be restricted to other islands, such as St. Lawrence and St. Matthew. Furthermore, the sample of Alaskan mammoths is very small compared to the sample from western Beringia (4 versus 49; 3 versus 30 used here), leaving many phylogeographic details of the eastern region in question and any conclusions about the relative isolation of the Qagnax̂ mammoth tentative.

One notable feature of our phylogenetic analysis is the placement of sample "Eu 40,900." In the analysis by Barnes et al. (2007), this Estonian sample appeared to represent a clade distinct from the Beringian mammoths. Our maximum likelihood tree (Fig. 2b) is in agreement with this conclusion. However, based on our Bayesian analysis, this sample falls within, but at the base of, clade 1 (Fig. 2c). We suspect that this is partially attributable to a single $G>A$ transition at position 15599, which the Estonian sample and Qagnax share to the exclusion of all other mammoths. This suggests that the Estonian mammoth does not represent a distinct third clade among woolly mammoths, and may in fact have its origins in eastern Beringia (along with other clade 1 mammoths). Again, our ML tree and the tree produced by Barnes et al. (2007) both suggest the same general topological scheme, and therefore more thorough sampling and rigorous phylogenetic procedures are required to resolve this discrepancy.

Initially, we used the Bayesian program BEAST v.1.4.6 (Drummond and Rambaut, 2006; Drummond et al., 2006) to calculate mutation rates and coalescent dates for various nodes within our trees, particularly the timing of common ancestry for the Alaskan mammoths and Qagnax in our dataset. We restricted the dataset to only mammoths with finite radiocarbon dates, and used a variety of model 
Table 2

Coverage map for base positions with $<100 \%$ consensus among sequencing reactions and/or that are unique to the Qagnax mammoth

\begin{tabular}{|c|c|c|c|c|c|c|c|c|c|c|c|c|c|c|c|c|c|c|c|c|c|c|c|c|c|c|c|c|c|c|c|c|c|c|c|c|c|c|c|c|c|}
\hline \multirow{5}{*}{$\mathrm{a}$} & 1 & 1 & 1 & 1 & 1 & 1 & 1 & 1 & 1 & 1 & 1 & 1 & 1 & 1 & 1 & 1 & 1 & 1 & 1 & 1 & 1 & 1 & 1 & 1 & 1 & 1 & 1 & 1 & 1 & 1 & 1 & 1 & 1 & 1 & 1 & 1 & 1 & 1 & 1 & 1 & 1 \\
\hline & 4 & 4 & 4 & 4 & 4 & 4 & 4 & 4 & 4 & 4 & 4 & 4 & 4 & 4 & 4 & 4 & 4 & 4 & 4 & 5 & 5 & 5 & 5 & 5 & 5 & 5 & 5 & 5 & 5 & 5 & 5 & 5 & 5 & 5 & 5 & 5 & 5 & 5 & 5 & 5 & 5 \\
\hline & 1 & 2 & 2 & 2 & 2 & 3 & 3 & 4 & 5 & 7 & 8 & 8 & 8 & 8 & 8 & 8 & 8 & 9 & 9 & 0 & 0 & 0 & 0 & 0 & 0 & 1 & 1 & 1 & 1 & 1 & 1 & 1 & 1 & 2 & 2 & 2 & 2 & 2 & 5 & 5 & 6 \\
\hline & 9 & 4 & 7 & 7 & 7 & 2 & 8 & 5 & 0 & 9 & 0 & 3 & 4 & 4 & 5 & 5 & 8 & 0 & 4 & 1 & 1 & 1 & 1 & 1 & 5 & 5 & 7 & 7 & 7 & 7 & 7 & 7 & 9 & 3 & 4 & 6 & 7 & 9 & 7 & 9 & 3 \\
\hline & 2 & 9 & 3 & 5 & 6 & 9 & 8 & 9 & 8 & 8 & 5 & 8 & 7 & 8 & 2 & 8 & 0 & 9 & 7 & 3 & 4 & 5 & 6 & 9 & 4 & 1 & 2 & 3 & 4 & 5 & 6 & 7 & 4 & 6 & 9 & 3 & 8 & 1 & 6 & 9 & 4 \\
\hline$b$ & $\mathbf{T}$ & C & A & $\mathbf{T}$ & $\mathbf{T}$ & $\mathbf{T}$ & C & C & C & $\mathrm{C}$ & C & C & $\mathrm{C}$ & $\mathbf{T}$ & C & C & C & C & $\mathbf{T}$ & $\mathbf{T}$ & A & G & G & G & G & $\mathbf{T}$ & A & A & $\mathrm{C}$ & C & A & G & C & C & C & G & C & C & A & $G^{f}$ & A \\
\hline \multirow{12}{*}{ c } & C &. & G & . & . & C &. &. &. & . &. &. &. & . & . & $\mathrm{T}$ & $\mathrm{T}$ & . & C & . &. & . & . & . &. & C & . & . & . & . & . & . & . & . & . & . & . & . & G & A & G \\
\hline & C & . & G & . & . & C & . & . & . & . & . & . & . & . & . & $\mathrm{T}$ & $\mathrm{T}$ & . & C & . & . & . & . & . & . & C & . & . & . & . & . & . & . & . & . & . & . & . & G & A & G \\
\hline & C & . & G & . & . & & . & . & . & . & . & . & . & . & . & $\mathrm{T}$ & $\mathrm{T}$ & . & C & . & . & . & . & . & . & $C$ & . & . & . & . &. & . & . & . & . & . & . & . & & & \\
\hline & C & . & G & . & . & & . & . & . & . & $\mathrm{T}$ & . & . & . & . & $\mathrm{T}$ & $\mathrm{T}$ & $\mathrm{T}$ & C & . & . & . & . & . & . & C & . & . & . & . & . & . & . & . & . & . & . & . & & & \\
\hline & $\mathrm{C}$ &. & G & . & . & & . & . &. & . & & . & . & . & . & $\mathrm{T}$ & $\mathrm{T}$ & & C & . & . & . & . & . & . & $C$ &. & . & . & . & . & . & . & . & . & . & . & . & & & \\
\hline & $\mathrm{C}$ & . & G & . & . & & . & . & $\mathrm{N}$ & $\mathrm{T}$ & & . & . & . & . & $\mathrm{T}$ & $\mathrm{T}$ & & & . & . & . & . & . & . & C & . & . & . & . & . & . & . & . & . & . & . & . & & & \\
\hline & & $\mathrm{T}$ & G & . & . & & . & $\mathrm{T}$ & & & & . & . & . & $\mathrm{T}$ & $\mathrm{T}$ & $\mathrm{T}$ & & & . & . & . & . & . & . & $C$ & . & $\mathrm{N}$ & $\mathrm{N}$ & $\mathrm{N}$ & . & . & . & . & . & $\mathrm{N}$ & $\mathrm{N}$ & . & & & \\
\hline & & $\mathrm{T}$ & G & . & . & & . & $\mathrm{Y}$ & & & & . & $\mathrm{T}$ & . & $\mathrm{T}$ & & $\mathrm{T}$ & & & . & . & . & . &. & A & & $\mathrm{N}$ & $\mathrm{N}$ & $\mathrm{N}$ & $\mathrm{N}$ & $\mathrm{N}$ & . & . & . & . & $\mathrm{N}$ & $\mathrm{N}$ & . & & & \\
\hline & & & G & : & : & & . & & & & & $\mathrm{T}$ & $\mathrm{T}$ & : & & & & & & . & . & . & . & . & A & & & & & & & . & . & . & . & & & . & & & \\
\hline & & & & & & & $\mathrm{T}$ & & & & & & & & & & & & & . & . & A & . & . & & & & & & & & . & . & $\mathrm{N}$ & $\mathrm{N}$ & & & G & & & \\
\hline & & & & & & & $\mathrm{T}$ & & & & & & & & & & & & & . & . & A & A & A & & & & & & & & . & $\mathrm{N}$ & $\mathrm{N}$ & $\mathrm{N}$ & & & & & & \\
\hline & & & & & & & & & & & & & & & & & & & & $\mathrm{N}$ & $\mathrm{N}$ & $\mathrm{N}$ & A & A & & & & & & & & $\mathrm{N}$ & $\mathrm{N}$ & & & & & & & & \\
\hline$d$ & 4 & 4 & 4 & 4 & 4 & 2 & 5 & 4 & 4 & 4 & 2 & 4 & 4 & 4 & 4 & 4 & 4 & 4 & 3 & 5 & 5 & 5 & 5 & 5 & 5 & 5 & 4 & 4 & 4 & 4 & 4 & 5 & 5 & 4 & 4 & 3 & 5 & 5 & 2 & 2 & 2 \\
\hline e & 5 & 4 & 4 & 4 & 4 & 2 & 6 & 8 & 4 & 6 & 4 & 6 & 6 & 6 & 5 & 5 & 4 & 4 & 4 & 7 & 7 & 7 & 7 & 7 & 5 & 7 & 4 & 4 & 4 & 4 & 4 & 8 & 8 & 8 & 8 & 4 & 6 & 6 & 2 & 2 & 2 \\
\hline
\end{tabular}

a Base position.

${ }^{\mathrm{b}}$ Consensus reference base among those available and listed in Table 3.

"Sequence calls from individual sequencing reactions; "." = identity $\mathrm{w} /$ reference base; ":" = gap; "N" = unknown base; "Y" = pyrimidine (C or T).

${ }^{\mathrm{d}}$ Number of independent extracts from which PCRs contributing template for sequencing were obtained.

eNumber of independent PCRs contributing template for sequencing.

fQagnâ shares an A at this position with sample "Eu 40900" - see text for discussion.

parameters similar to those used by Barnes et al. (2007). However, there was considerable variation in the calculated evolutionary rates and estimated dates of coalescence. Results varied depending not only on specified model parameters, but particularly on the size of the dataset (all available mammoths vs. our truncated set [see Materials and methods section]). Calculations were also greatly affected by the inclusion or exclusion of an outgroup sequence and whether or not constraints on the coalescent times were implemented (e.g., between the Asian elephant and mammoths). This is not surprising, as there has been considerable recent debate (Woodhams, 2006; Ho et al., 2007; Bandelt, 2007) on the reliability of calculated evolutionary rates, such that temporal inferences are especially affected by the relative depth of inquiry (i.e., timing of samples-outgroup common ancestry). However, there are good reasons to believe that sequence data from a closely related species would aid in temporal inferences (Ho and Larson, 2006). Asian elephants and woolly mammoths shared common ancestry roughly 6.7 million years ago (Rohland et al., 2007), while Columbian (Mammuthus columbi) and woolly mammoths likely shared common ancestry approximately 2 million years ago (Agenbroad, 2005). This recent shared ancestry potentially makes Columbian mammoths a more suitable outgroup species for resolving temporal issues within mammoth phylogeny. We are currently

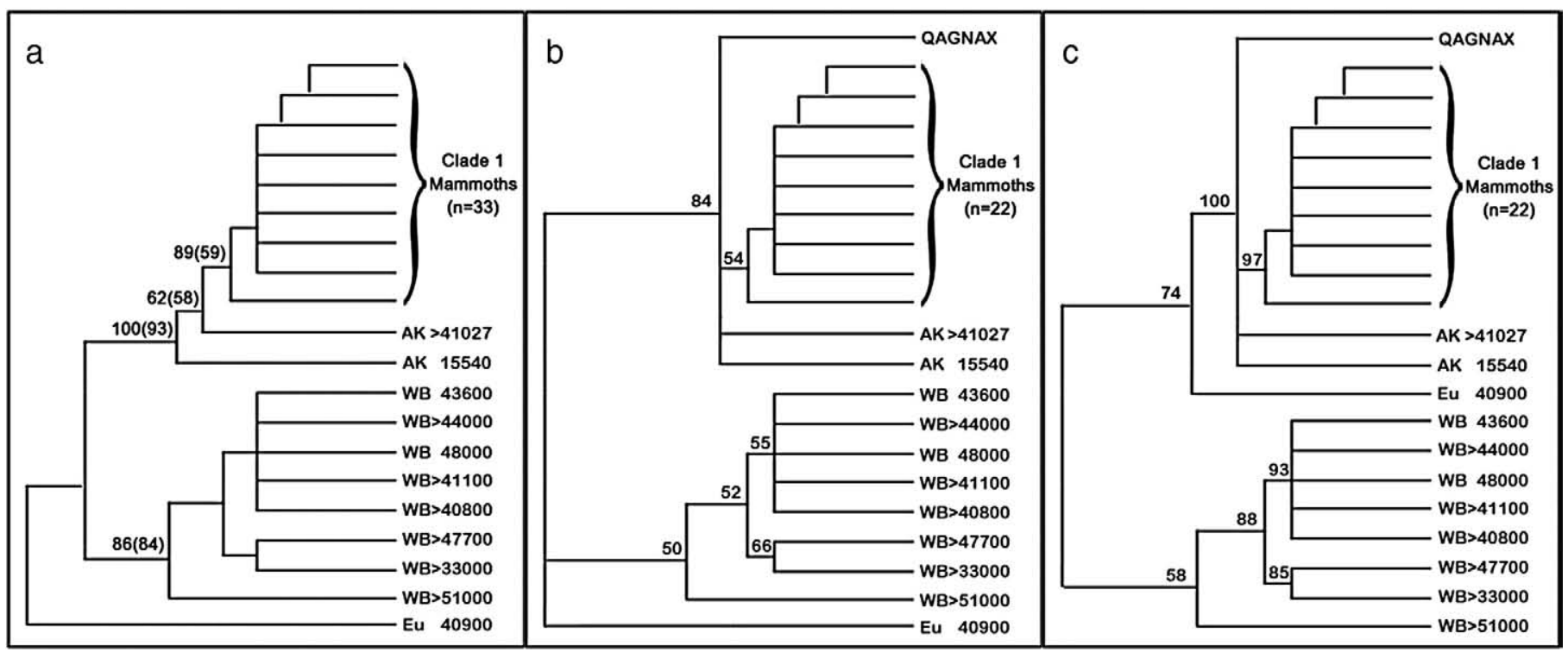

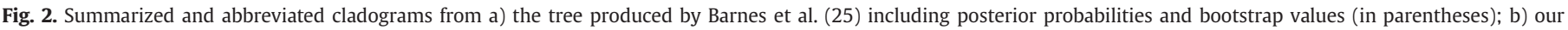

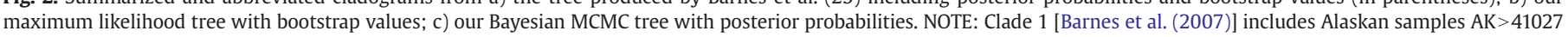
and AK 15540, but are separated to show their comparison to the Qagnâx mammoth. 
acquiring mitochondrial DNA sequences from a Columbian mammoth (M. columbi) in our laboratory to address this issue.

In conclusion, our analysis indicates that the mitochondrial DNA of the Qagnax mammoth is substantially derived relative to other mammoth sequence obtained to date. Considering the mid-Holocene age of the specimen and its isolation from the Alaskan mainland, this unique sequence may be the result of local insular evolution during the early Holocene. However, there is good evidence to suggest that its isolation from other Alaskan mammoths occurred well before the LGM, and thus before the separation of St. Paul Island from the Alaskan mainland (Guthrie, 2004). It is possible that the specimen represents a "land bridge subclade" that was relatively isolated from mainland mammoths in both eastern and western Beringia for a considerable period. However, the extent to which eastern Beringian mammoth populations were geographically structured in this way, and the ecological factors that might explain it, remain to be deciphered. Furthermore, we have yet to fully understand the dynamics and pace of recent evolution within the woolly mammoth lineage, leaving the temporal and ecological context of mammoth dispersals and extinctions (Barnes et al., 2007) uncertain. We see potential resolution to these questions, mainly by using genetic sequences from additional Alaskan woolly mammoths, as well as other mammoth species (e.g., M. columbi), to improve our temporal inferences in woolly mammoth phylogeography.

\section{Materials and methods}

\subsection{DNA extraction}

An enamel plate from one maxillary molar of woolly mammoth specimen number SPC-03-102D from Qagnax Cave was selected for mtDNA extraction. This specimen was stored at room temperature until our experiments began, shortly after which it was kept frozen. A fragment of the enamel plate was used for the extraction. We performed all ancient nucleic acid extractions using the ancient DNA-dedicated facilities in the Molecular Anthropology Laboratory of the Department of Anthropology, University of Utah, Salt Lake City, Utah, USA. No DNA research has been performed on other mammoth specimens or modern elephant samples in the laboratory. Anti-contamination procedures included the use of UV irradiation of all experimental materials (tubes, pipettes, hood surfaces, etc.), cleaning of all working surfaces with $6 \%$ bleach solution, and the use of gloves, sleeves, face masks, hair nets, and laboratory coats. We performed all extractions with "blank" solutions as negative controls in order to detect contamination.

Approximately $0.5 \mathrm{~g}( \pm 0.2 \mathrm{~g})$ of tooth material (enamel with residual dentin) was used in each of nine extraction digests (\#1-9). Tooth fragments were reduced to powder and UV-irradiated for 5 to $15 \mathrm{~min}$ prior to chemical digestion in a solution of 2-3 $\mathrm{ml} 0.5 \mathrm{M}$ EDTA and $50-130 \mathrm{ml}$ of $20 \mathrm{mg} / \mathrm{ml}$ proteinase $\mathrm{K}$ for $18-72 \mathrm{~h}$ at a temperature of $37-53.5^{\circ} \mathrm{C}$. Roughly $1 \mathrm{ml}$ of digest supernatants were isolated and subjected to silica purification using the GENECLEAN ${ }^{\circledR}$ for Ancient DNA kit (Q-BIOgene). Each individual purification (between 2 and 3 for each digest) yielded $100 \mathrm{ml}$ of purified template.

\subsection{DNA amplification}

We targeted the cytochrome $b$ gene, adjacent tRNA-Pro and tRNAThr genes, and a section of the D-loop (nucleotide positions 14151 to 15784) of the mitochondrial genome for this analysis. We designed 30 primer pairs, divided into four groups (Table 1) - group \#1, consisting of thirteen overlapping fragments that cover the entire cytochrome $b$ gene as well as short flanking regions; group \#2, consisting of eight fragments that were used to resolve coverage or sequencing consensus needs; group \#3, consisting of three fragments used solely for additional experimental material, not necessary for consensus resolution; and group \#4, consisting of six fragments meant to obtain sequence comparable to those obtained by Barnes et al. (2007) (Table 1).
PCR reactions were prepared in a UV-irradiated, HEPA-filtered, and positive-pressurized laboratory, and performed in a HEPA-filtered PCRdedicated workstation, its surfaces frequently UV-irradiated and bleached before and after use. Laboratory-dedicated garb as described previously was worn at all times. As with extractions, we included blank solutions for each set of amplifications in order to detect contamination.

Amplifications were performed in $25 \mathrm{ml}$ volumes with 1-1.25 units AmpliTaq Gold ${ }^{\circledR}, 1 \times$ AmpliTaq Gold ${ }^{\circledR}$ PCR buffer (Applied Biosystems), $0.2 \mathrm{mM}$ each dNTP, $1.5 \mathrm{mM} \mathrm{MgCl} 2,0.1 \mathrm{mg} / \mathrm{ml}$ bovine serum albumin, $0.2 \mathrm{mM}$ each primer, and 3-5 $\mathrm{ml}$ of purified DNA template. The following thermal cycling parameters were used: initial incubation at $95{ }^{\circ} \mathrm{C}$ for $5-13 \mathrm{~min}$, followed by $40-48$ cycles of $95^{\circ} \mathrm{C}$ for $30-45 \mathrm{~s}, 54-$ $58{ }^{\circ} \mathrm{C}$ for $30-90 \mathrm{~s}$, and $72{ }^{\circ} \mathrm{C}$ for $45-120 \mathrm{~s}$, ending with a final $3-5 \mathrm{~m}$ extension period at $72{ }^{\circ} \mathrm{C}$. Two products required reamplification for an additional 30-33 cycles. Products were visualized by electrophoresis on $2 \%$ agarose gels stained with ethidium bromide or SYBR ${ }^{\circledR}$ Green under UV light.

\subsection{DNA sequencing}

We purified successful amplifications using the QIAquick PCR Purification Kit (Qiagen). The Health Sciences Center Core Research Facilities at the University of Utah provided sequences using ABI3170 and ABI3100 sequencing platforms. We visually examined the experimental chromatographs using the Sequencher ${ }^{\mathrm{TM}}$ v.4.5 alignment software and corrected misreads where discrepancies between chromatographic peaks and automated calls were evident. We then compared the consensus Qagnax̂ sequence to all available definitive mammoth sequences (Yang et al., 1996; Ozawa et al., 1997; Noro et al., 1998; Greenwood et al., 1999; Debruyne et al., 2003; Krause et al., 2006; Rogaev et al., 2006; Barnes et al., 2007; Gilbert et al., 2007) in order to identify notable polymorphisms (Table 3).

\subsection{Phylogenetic analysis}

Phylogenetic analysis was restricted to the last 714 bases of the sequence obtained here, for which Krause et al. (2006), Rogaev et al. (2006), Barnes et al. (2007) and Gilbert et al. (2007) provide a combined total of 53 comparable woolly mammoth DNA sequences. Originally, we included all of these sequences in both our Bayesian and maximum likelihood phylogenetic analyses to provide the most thorough analysis possible. However, the results from these initial analyses indicated that all of the Siberian mammoths sequenced by Gilbert et al. (2007) fall within "clade 1" as defined by Barnes et al. (2007) (see Fig. 2a). Because our final analysis was not concerned with the shallower topology within this clade, and in order to expedite computation during the full-heuristic ML bootstrap, we opted to reduce the dataset by randomly selecting and eliminating 20 mammoth sequences from this clade, but conserving the basal Alaskan sequences, resulting in a final representative sample of 22 comparative sequences (indicated in Table 3). Both the initial, full-set and the final, truncated-set analyses (discussed below) resulted in identical topological features, and so we report only the latter.

For topological assay of the truncated set of sequences, maximum likelihood analysis was performed using PAUP v4.0 (Swofford, 2002). We used an Asian elephant (Elephas maximus) sequence obtained by Rogaev et al. (2006) as an outgroup. ML analysis began with the generation of a neighbor-joining tree, followed by a heuristic search conforming to the Hasegawa-Kishino-Yano (HKY) model of sequence evolution, with 4 gamma rate categories $(+G)$ and an assumed proportion of invariant sites $(+\mathrm{I})$. The estimated parameters from this first run were then implemented in another heuristic search. A 1000replicate full heuristic bootstrap on the subsequent ML tree was performed as well. Bayesian phylogeny was calculated using the 
Table 3

Reference Mammuthus primigenius mtDNA sequences used in this study for alignment, identification of segregating sites, and phylogenetic analyses

\begin{tabular}{|c|c|c|c|c|c|c|}
\hline Reference & Location $^{\mathrm{a}}$ & $\frac{\mathrm{C}^{14} \text { age }}{(\mathrm{yr} \mathrm{BP})^{\mathrm{b}}}$ & $\frac{\text { Length }}{\text { (bases) }^{c}}$ & Nucleotide Positions $^{d}$ & For Phyl? & Tree ID \\
\hline This study & St. Paul Is. & 5725 & 1652 & $14106-15757$ & $\mathrm{Y}$ & Qagnax \\
\hline Yang et al. (1996) & Lyakhov Is. & $>46,000$ & 228 & 14242-14469 & $\mathrm{N}$ & - \\
\hline Yang et al. (1996) & Fairbanks & $\sim 20,000$ & 228 & $14242-14469$ & $\mathrm{~N}$ & - \\
\hline Ozawa et al. (1997) & Magadan & 40,000 & 1005 & $14151-15155$ & $\mathrm{~N}$ & - \\
\hline Noro et al. (1998) & Taimyr Pen. & $>25,000$ & 1137 & $14151-15287$ & $\mathrm{~N}$ & - \\
\hline Greenwood et al. (1999) & Engineer Crk. & 13,775 & 307 & $14246-14552$ & $\mathrm{~N}$ & - \\
\hline Greenwood et al. (2001) & Chekurovka & 26,000 & 139 & $14414-14552$ & $\mathrm{~N}$ & - \\
\hline Greenwood et al. (2001) & Wrangel Is. & 4590 & 139 & $14414-14552$ & $\mathrm{~N}$ & - \\
\hline Debruyne et al. (2003) & Lyakhov Is. & $>49,000$ & 561 & $14246-15086$ & $\mathrm{~N}$ & - \\
\hline Krause et al. (2006) & Berelekh & 12,170 & 1652 & $14106-15757$ & $\mathrm{Y}$ & Clade 1 \\
\hline Rogaev et al. (2006) & Chukotka & 32,850 & 1652 & $14106-15757$ & $\mathrm{~N}$ & - \\
\hline Barnes et al. (2007) & Buor-Khaya & $>40,800$ & 714 & 15044-15757 & $\mathrm{Y}$ & $W B>40800$ \\
\hline Barnes et al. (2007) & Buor-Khaya & $>41,100$ & 714 & $15044-15757$ & $\mathrm{Y}$ & $W B>41100$ \\
\hline Barnes et al. (2007) & Gold Crk. & $>41,027$ & 714 & 15044-15757 & $\mathrm{Y}$ & $\mathrm{AK}>41027$ \\
\hline Barnes et al. (2007) & Ban Crk. & 15,540 & 714 & $15044-15757$ & $\mathrm{Y}$ & AK 15540 \\
\hline Barnes et al. (2007) & Ester Crk. & 16,789 & 714 & 15044-15757 & $\mathrm{N}$ & - \\
\hline Barnes et al. (2007) & Koosa (Estonia) & 40,900 & 714 & $15044-15757$ & $\mathrm{Y}$ & Eu 40900 \\
\hline Barnes et al. (2007) & Bykovsky Pen. & 14,600 & 714 & $15044-15757$ & $\mathrm{~N}$ & - \\
\hline Barnes et al. (2007) & Bykovsky Pen. & 19,200 & 714 & $15044-15757$ & $\mathrm{~N}$ & - \\
\hline Barnes et al. (2007) & Bykovsky Pen. & 20,200 & 714 & $15044-15757$ & $\mathrm{Y}$ & Clade 1 \\
\hline Barnes et al. (2007) & Bykovsky Pen. & $>44,000$ & 714 & $15044-15757$ & $\mathrm{~N}$ & - \\
\hline Barnes et al. (2007) & Bykovsky Pen. & 13,100 & 714 & $15044-15757$ & $\mathrm{~N}$ & - \\
\hline Barnes et al. (2007) & Bykovsky Pen. & $>44,300$ & 714 & 15044-15757 & $\mathrm{N}$ & - \\
\hline Barnes et al. (2007) & Bykovsky Pen. & 30,300 & 714 & $15044-15757$ & $\mathrm{~N}$ & - \\
\hline Barnes et al. (2007) & Bykovsky Pen. & 29,400 & 714 & $15044-15757$ & $\mathrm{~N}$ & - \\
\hline Barnes et al. (2007) & Bykovsky Pen. & 28,900 & 714 & 15044-15757 & $\mathrm{Y}$ & Clade 1 \\
\hline Barnes et al. (2007) & Bykovsky Pen. & 34,000 & 714 & 15044-15757 & $\mathrm{Y}$ & Clade 1 \\
\hline Barnes et al. (2007) & Bykovsky Pen. & 33,800 & 714 & $15044-15757$ & $\mathrm{~N}$ & - \\
\hline Barnes et al. (2007) & Bykovsky Pen. & 24,300 & 714 & $15044-15757$ & $\mathrm{Y}$ & Clade 1 \\
\hline Barnes et al. (2007) & Bykovsky Pen. & 32,800 & 714 & 15044-15757 & $\mathrm{N}$ & - \\
\hline Barnes et al. (2007) & Lyakhov Is. & 32,500 & 714 & 15044-15757 & $\mathrm{N}$ & - \\
\hline Barnes et al. (2007) & Lyakhov Is. & 37,800 & 714 & $15044-15757$ & $\mathrm{~N}$ & - \\
\hline Barnes et al. (2007) & Lyakhov Is. & $>35,600$ & 714 & 15044-15757 & $\mathrm{Y}$ & Clade 1 \\
\hline Barnes et al. (2007) & Lyakhov Is. & $>42,400$ & 714 & 15044-15757 & $\mathrm{N}$ & - \\
\hline Barnes et al. (2007) & Lyakhov Is. & $>33,000$ & 714 & 15044-15757 & $\mathrm{Y}$ & $W B>33000$ \\
\hline Barnes et al. (2007) & Lyakhov Is. & 40,200 & 714 & $15044-15757$ & $\mathrm{Y}$ & Clade 1 \\
\hline Barnes et al. (2007) & Lyakhov Is. & $>47,700$ & 714 & 15044-15757 & $\mathrm{Y}$ & $W B>47700$ \\
\hline Barnes et al. (2007) & Lyakhov Is. & 25,900 & 714 & $15044-15757$ & $\mathrm{Y}$ & Clade 1 \\
\hline Barnes et al. (2007) & Lyakhov Is. & 48,000 & 714 & $15044-15757$ & $\mathrm{Y}$ & WB 48000 \\
\hline Barnes et al. (2007) & Lyakhov Is. & $>51,000$ & 714 & $15044-15757$ & $\mathrm{Y}$ & $W B>51000$ \\
\hline Barnes et al. (2007) & Lyakhov Is. & $>44,000$ & 714 & $15044-15757$ & $\mathrm{Y}$ & $W B>44000$ \\
\hline Barnes et al. (2007) & Lyakhov Is. & $>47,000$ & 714 & $15044-15757$ & $\mathrm{~N}$ & - \\
\hline Barnes et al. (2007) & Lyakhov Is. & 12,030 & 714 & $15044-15757$ & $\mathrm{Y}$ & Clade 1 \\
\hline Barnes et al. (2007) & Lyakhov Is. & 12,500 & 714 & $15044-15757$ & $\mathrm{Y}$ & Clade 1 \\
\hline Barnes et al. (2007) & Lyakhov Is. & 43,600 & 714 & 15044-15757 & $\mathrm{Y}$ & WB 43600 \\
\hline Barnes et al. (2007) & Lena Delta & 30,200 & 714 & 15044-15757 & $\mathrm{N}$ & - \\
\hline Barnes et al. (2007) & Kamchatka & 45,200 & 714 & $15044-15757$ & $\mathrm{Y}$ & Clade 1 \\
\hline Barnes et al. (2007) & Lyakhov Is. & 36,610 & 714 & $15044-15757$ & $\mathrm{Y}$ & Clade 1 \\
\hline Barnes et al. (2007) & Khatanga & 46,600 & 714 & $15044-15757$ & $\mathrm{Y}$ & Clade 1 \\
\hline Barnes et al. (2007) & Wrangel Is. & 25,890 & 714 & $15044-15757$ & $\mathrm{Y}$ & Clade 1 \\
\hline Barnes et al. (2007) & Lugovskoe & 13,455 & 714 & $15044-15757$ & $\mathrm{~N}$ & - \\
\hline Barnes et al. (2007) & Kochegur & 25,300 & 714 & $15044-15757$ & $\mathrm{~N}$ & - \\
\hline Gilbert et al. (2007) & (Siberia) & ND & 1652 & 14106-15757 & $\mathrm{Y}$ & Clade 1 \\
\hline Gilbert et al. (2007) & Taimyr Pen. & 20,380 & 1652 & $14106-15757$ & $\mathrm{~N}$ & - \\
\hline Gilbert et al. (2007) & Taimyr Pen. & 20,620 & 1652 & $14106-15757$ & $\mathrm{Y}$ & Clade 1 \\
\hline Gilbert et al. (2007) & (Siberia) & 18,545 & 1652 & $14106-15757$ & $\mathrm{Y}$ & Clade 1 \\
\hline Gilbert et al. (2007) & (Siberia) & ND & 1652 & 14106-15757 & $\mathrm{Y}$ & Clade 1 \\
\hline Gilbert et al. (2007) & Magadan & 46,900 & 1652 & 14106-15757 & $\mathrm{Y}$ & Clade 1 \\
\hline Gilbert et al. (2007) & Lena Delta & 35,800 & 1652 & $14106-15757$ & $\mathrm{Y}$ & Clade 1 \\
\hline Gilbert et al. (2007) & Gydan & 17,125 & 1652 & $14106-15757$ & $\mathrm{Y}$ & Clade 1 \\
\hline Gilbert et al. (2007) & Novosibirsk & 50,200 & 1652 & $14106-15757$ & $\mathrm{~N}$ & - \\
\hline Gilbert et al. (2007) & Indigirka & 24,740 & 1652 & $14106-15757$ & $\mathrm{Y}$ & Clade 1 \\
\hline
\end{tabular}

a Locations in parentheses have only general regional provenance.

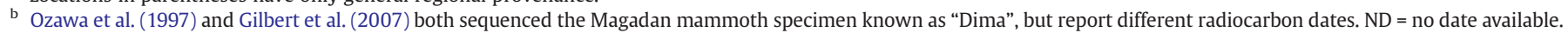

c Includes only the sequence regions used for comparison to the Qagnax sequence. Krause et al. (2006), Rogaev et al. (2006) and Gilbert et al. (2007) obtained whole mitochondrial genome sequences, while others sequenced other sections of the mitochondrial and nuclear genomes not examined in this study.

d Nucleotide positions used in this study coincide with the mtDNA map used in GenBank to designate gene regions. Debruyne et al. (2003) sequenced only certain sections of the region listed, hence the short total sequence length reported here.

e The sequences used in phylogenetic analysis. Only the last 714 bases of the Qagnax̂ sequence were used for phylogenetic analysis, and reference sequence selection reflects this constraint. Furthermore, a random sample of 21/41 of the mammoths that fell into "clade1" defined by Barnes et al. (2007) were selected for use phylogenetic analysis.

program Mr Bayes v.3.1.2 (Huelsenbeck and Ronquist, 2001), which included a Monte Carlo Markov Chain search conforming to the HKY+ $\mathrm{G}+\mathrm{I}$ model parameters. This program involved 10 million generations with samples drawn every 100 generations. The final standard error of the split frequencies was 0.003 . Posterior probabilities and consensus tree topology were assayed after a $10 \%$ burn-in. 


\section{Acknowledgments}

We thank Joan Coltrain, Chandler Gatenbee, Alan Rogers, Silvia Smith and Susan Spencer for assistance and insightful discussion. M.T.P. Gilbert and H. Poinar provided helpful reviews. Elizabeth Marchani performed pilot work on this specimen. Funding for the mtDNA analysis was provided by National Science Foundation Grants OPP-0327641 and OPP-0637246 to O'Rourke, and an NSF Graduate Fellowship to Enk. Funding for fieldwork at Qagnax̂ Cave was provided by a University of Alaska Anchorage Faculty Development grant to Veltre, Yesner, and Crossen. Darden Hood of Beta Analytic Inc. provided radiocarbon dating results on the mammoth remains from Qagnax Cave. The TDX Corporation, the Aleut village corporation of St. Paul, Alaska, gave permission for fieldwork and analysis, as well as in-kind support for this project. The Qagnax̂ mammoth DNA sequence is submitted under accession ID \#FJ655900 on GenBank. Primer sequences are available upon request.

\section{References}

Agenbroad, L.D., 2003. In: Reumer, J.W.F., de Vos, J., Mol, D. (Eds.), Advances in Mammoth Research. Deinsea, vol. 9, pp. 1-16.

Agenbroad, L.D., 2005. North American proboscideans: mammoths: the state of knowledge, 2003. Quat. Int. 126-128, 73-92.

Bandelt, H.-J., 2007. Time dependency of molecular rate estimates: tempest in a teacup. Heredity 100, 1-2.

Barnes, I., Shapiro, B., Lister, A., Kuznetsova, T., Sher, A., Guthrie, D., Thomas, M.G., 2007. Genetic structure and extinction of the woolly mammoth, Mammuthus primigenius. Curr. Biol. 18, 1072-1075.

Crossen, K.J., Graham, R.W., Veltre, D.W., Yesner, D.R., 2003. A Pribilof Island Cave: Late Quaternary Mammal Bone Assemblages from St. Paul Island, Bering Sea, Alaska. Geol. Soc. Am. Abstr. with Prog., vol. 35, p. 424.

Crossen, K.J., Veltre, D.W., Yesner, D.R., Graham, R.W., 2005. 5,700-year-old Mammoth Remains from the Pribilof Islands, Alaska: Last Outpost of North American Megafauna. Geol. Soc. Am. Abstr. with Prog., vol. 37, p. 463.

Debruyne, R., Barriel, V., Tassy, P., 2003. Mitochondrial cytochrome $b$ of the Lyakhov mammoth (Proboscidea, Mammalia): new data and phylogenetic analyses of Elephantidae. Mol. Phylogenet. Evol. 26 421-434.17.

Debruyne, R., Chu, G., King, C.E., Bos, K., et al., 2008. Out of America: ancient DNA evidence for a new world origin of Late Quaternary woolly mammoths. Curr. Biol. 18,1320-1326.

Drummond, A.J., Rambaut, A., 2006. BEAST v1.4, avail. fr. http://beast.bio.ed.ac.uk.

Drummond, A.J., Ho, S.Y., Phillips, M.J., Rambaut, A., 2006. Relaxed phylogenetics and dating with confidence. PLoS Biol. 4, 88.

Gilbert, M.T.P., Willerslev, E., Hansen, A., Barnes, I., Rudbeck, L., Lynnerup, N., Cooper, A., 2003a. Distribution patterns of postmortem damage in human mitochondrial DNA. Am. J. Hum. Genet. 72, 32-47.

Gilbert, M.T.P., Hansen, A., Willerslev, E., Barnes, I., Rudbeck, L., Lynnerup, N., Cooper, A., 2003b. Characterization of genetic miscoding lesions caused by postmortem damage. Am. J. Hum. Genet. 72, 48-61.

Gilbert, M.T.P., Binladen, J., Miller, W., Wiuf, C., Willerslev, E., Poinar, H., Carlson, J., Leebens-Mack, J., Schuster, S., 2007. Whole-genome shotgun sequencing of mitochondria from ancient hair shafts. Nucl. Acids Res. 35, 1-10.

Gilbert, M.T.P., Drautz, D.I., Lesk, A.M., Ho, S.Y.W., et al., 2008. Intraspecific phylogenetic analysis of Siberian woolly mammoths using complete mitochondrial genomes. PNAS 105, 8327-8332.

Greenwood, A.D., Capelli, C., Possnert, G., Pääbo, S., 1999. Nuclear DNA sequences from late Pleistocene megafauna. Mol. Biol. Evol. 16, 1466-1473.

Greenwood, A.D., Lee, F., Capelli, C., DeSalle, R., Tikhonov, A., Marx, P.A., MacPhee, R.D.E. 2001. Evolution of Endogenous Retrovirus-like Elements of the Woolly Mammoth (Mammuthus primigenius) and its Relatives. Mol. Biol. Evol. 18, 840-857.
Grover, M.A., Tedor, R., 2006. A mid-Holocene mammoth tusk from St. Paul Island Alaska Anthrop. Ass. Prog. Abstr. (Poster).

Guthrie, R.D., 2004. Radiocarbon evidence of mid-Holocene mammoths stranded on an Alaskan Bering Sea island. Nature 249, 746-749.

Haynes, G.W., 1991. Mammoths, Mastodonts, and Elephants: Biology, Behavior, and the Fossil Record. Cambridge University Press, Cambridge.

Ho, S., Larson, G., 2006. Molecular clocks: when times are a - changin'. Trends Genet 22, 79-83.

Ho, S.Y.W., Shapiro, B., Phillips, M.J., Cooper, A., Drummond, A.J., 2007. Evidence for time dependency of molecular rate estimates. Syst. Biol. 56, 515-522.

Huelsenbeck, J.P., Ronquist, F., 2001. MRBAYES: Bayesian inference of phylogenetic trees. Bioinform 17, 754-755.

Krause, J., Dear, P.H., Pollack, J.L., Slatkin, M., Spriggs, H., Barnes, I., Lister, A.M., Ebersberger, I., Pääbo, S., Hofrieter, M., 2006. Multiplex amplification of the mammoth mitochondrial genome and the evolution of the Elephantidae. Nature 439, 724-727.

Lister, A.M., 1996. In: Shoshani, J., Tassy, P. (Eds.), The Proboscidea: Evolution and Palaoecology of Elephants and their Relatives. Oxford University Press, Oxford, pp. 203-213.

Maglio, V.J., 1973. Origin and evolution of the Elephantidae. Trans. Am. Philos. Soc. 63, 1-149 (Philadelphia).

Manley, William F., 2002. Postglacial Flooding of the Bering Land Bridge: a Geospatial Animation v.1. Institute for Arctic and Alpine Research, University of Colorado, Boulder. (http://instaar.colorado.edu/QGISL/bering_land_bridge).

Noro, M., Masuda, R., Dubrovo, I.A., Yoshida, M.C., Kato, M., 1998. Molecular phylogenetic inference of the woolly mammoth Mammuthus primigenius, based on complete sequences of mitochondrial cytochrome $b$ and 12S ribosomal RNA genes. J. Mol. Evol. 46, 314-326.

Ozawa, T., Hayashi, S., Mikhelson, V.M., 1997. Phylogenetic position of mammoth and Steller's Sea Cow within Tethytheria demonstrated by mitochondrial DNA sequences. J. Mol. Evol. 44, 406-413.

Preble, E.A., 1923. In: Preble, E.A., McAtee, W.L. (Eds.), A Biological Survey of the Pribilof Islands, Alaska, Part I: Birds and Mammals. N Am Fauna, vol. 46, pp. 102-120.

Ray, C.E., 1971. Polar bear and mammoth on the Pribilof Islands. Arctic 24, 9-18.

Rogaev, E.I., Moliaka, Y.K., Malyarchuk, B.A., Kondrashov, F.A., Derenko, M.V., Chumakov, I., Grigorenko, A.P., 2006. Complete mitochondrial genome and phylogeny of the Pleistocene mammoth Mammuthus primigenius. PLoS Biol. 5, 403-410.

Rohland, N., Malaspinas, A.-S., Pollack, J.L., Slatkin, M., Matheus, P., Hofreiter, M., 2007. Proboscidean mitogenomics: chronology and mode of elephant evolution using mastodon as outgroup. PLoS Biol. 5, e207.

Stanley-Brown, J., 1892. Geology of the Pribilof Islands. Geol. Soc. Amer. Bull. 3, 496-500

Stuart, A.J., Sulerzhitsky, L.D., Orlova, L.A., Kuzmin, Y.V., Lister, A.M., 2002. The latest woolly mammoths (Mammuthus primigenius Blumenbach) in Europe and Asia: a review of the current evidence. Quat. Sci. Rev. 21, 1559-1569.

Swofford, D., 2002. PAUP* Phylogenetic Analysis Using Parsimony (and Other Methods) v4.0 beta. Sinauer Associates, Sunderland, MA.

Veltre, D.W., McCartney, A.P., 2002. Russian exploitation of Aleuts and fur seals: the archaeology of eighteenth - and earl - nineteenth - century settlements in the Pribilof Islands, Alaska. Hist. Archaeol. 36, 8-17.

Veltre, D.W., Yesner, D.R., Crossen, K.J., Graham, R.W., 2004. Late Pleistocene/Holocene mammal bone assemblages from a cave on St. Paul Island: implications for paleoclimatic change and human occupation of the Bering Sea region. Alaska Anthropol. Assoc. Prog. Abstr. 27, 13.

Veltre, D.W., Yesner, D.R., Crossen, K.J., Graham, R.W., Coltrain, J.B., 2008. Patterns of faunal extinction and paleoclimatic change from mid - Holocene mammoth and polar bear remains, Pribilof Islands, Alaska. Quat. Res. 70, 40-50.

Woodhams, M., 2006. Can deleterious mutations explain the time dependency of molecular rate estimates? Mol. Biol. Evol. 23, 2271-2273.

Yang, H., Golenberg, E.M., Shoshani, J., 1996. Phylogenetic resolution within the Elaphantidae using fossil DNA sequence from the American mastodon (Mammut americanum) as an outgroup. Proc. Nat. Acad. Sci. 93, 1190-1194.

Yesner, D.R., Veltre, D.W., Crossen, K.J., Graham, R.W., 2005a. Mid - Holocene mammoth remains from Qagnax' Cave, Pribilof Islands, Alaska: implications for megafaunal extinction and peopling of the Americas. Soc. Am. Arch. Prog. Abstr. 70, 317-318.

Yesner, D.R., Veltre, D.W., Crossen, K.J., Graham, R.W., 2005b. In: Agenbroad, L.R. Symington, S. (Eds.), The World of Elephants: Short Papers and Abstracts of the 2nd International Congress. Mammoth Site Scientific Papers, vol. 4, pp. 200-204. 